\title{
COMUNICAÇÃO
}

\section{VARIABILIDADE EM DEZ POPULAÇÕES DE Hemileia vastatrix EM RELAÇÃO À GERMINAÇÃ̃O E AO COMPRIMENTO DO TUBO GERMINATIVO EM QUATRO TEMPERATURAS}

\author{
Variability in ten populations of Hemileia vastatrix for germination and germinative tube \\ length under four temperatures
}

\author{
Maria Eloisa Salustiano', Edson Ampélio Pozza², Antônio Carlos Ferraz Filho \\ Alex Oliveira Botelho ${ }^{4}$, Eduardo Alves ${ }^{2}$
}

\begin{abstract}
RESUMO
Neste trabalho, objetivou-se verificar o efeito da temperatura na germinação e no comprimento do tubo germinativo em diferentes populações de H. vastatrix (PHVs), sob quatro temperaturas. Realizou-se um bioensaio com dez PHVs, com suspensão de urediniósporos a $0,5 \mathrm{mg} / \mathrm{mL}$ em solução aquosa $(0,05 \%)$ de tween 80 . Duas gotas de cada suspensão foram depositadas em lâminas de microscópio recobertas com camada de poliestireno e colocadas em gerbox contendo papel de filtro umedecido para constituir câmara úmida. Os gerboxes foram mantidos fechados, no escuro, a $15^{\circ} \mathrm{C}, 20^{\circ} \mathrm{C}, 25^{\circ} \mathrm{C}$ e $30^{\circ} \mathrm{C}$, por 24 horas. $\mathrm{O}$ ensaio foi conduzido em fatorial $10 \times 4$, sendo dez isolados, quatro temperaturas e duas repetições. Avaliaram-se a germinação e o comprimento do tubo germinativo. Houve variabilidade entre as PHVs quanto à temperatura ótima para germinação e alongamento do tubo germinativo.
\end{abstract}

Termos para indexação: Ferrugem, Coffea arabica, populações.

\begin{abstract}
The objective of this work was to verify the effect of temperature in germination and germ tube length in different populations of $H$. vastatrix (PHVs) temperatures. A bioassay was performed with ten PHVs, using an urediniospore suspension of at $0.5 \mathrm{mg} / \mathrm{mL}$ in aqueous solution $(0.05 \%)$ of tween 80 . Two drops of each suspension was deposited on a microscope coverslip, covered with a polystyrene layer and incubated in gerbox containing a watered filter paper to work as a wet chamber. The gerbox was kept closed, in the dark, at $15,20,25$ and $30^{\circ} \mathrm{C}$ for 24 hours. The assay was carried out in a factorial design $10 \mathrm{x} 4$, with ten isolates, four temperatures and two replicates represented by two drops of the suspension. Germination percentage and germ tube length were assessed. There was variability among PHVs for the optimum temperature for germination and elongation of the germ tube.
\end{abstract}

Index terms: Rust, Coffea Arabica, population of Hemileia vastatrix.

(Recebido em 31 de julho de 2006 e aprovado em 22 de março de 2007)

O fungo biotrófico Hemileia vastatrix Berk. et Br. é o agente etiológico da ferrugem, a principal doença do cafeeiro em todas as regiões produtoras do mundo onde existem diferenças em relação às variáveis climáticas. Essas diferenças podem influenciar a biologia do patógeno (ZADOKS \& SCHEIN, 1979). Uma fase crítica para $H$. vastatrix é a germinação do urediniósporo, na qual a temperatura e o molhamento foliar são variáveis climáticas essenciais para o processo. A maioria dos trabalhos cita temperaturas entre $22^{\circ} \mathrm{C}$ a $24^{\circ} \mathrm{C}$ como ideais para ocorrer maior porcentagem de germinação de urediniósporos. Segundo Dejong et al. (1987), Rayner (1972) e Saccas \& Charpentier (1971), a $22^{\circ} \mathrm{C}$ ocorre a máxima porcentagem de germinação, porém, na literatura encontram-se outros valores. Dejong et al. (1987) citam, a $22^{\circ} \mathrm{C}, 64 \%$ de germinação. Segundo Akutsu (1981), a $25^{\circ} \mathrm{C}$ ocorreram $100 \%$ de germinação e completa inibição a $32,5^{\circ} \mathrm{C}$ e $12,5^{\circ} \mathrm{C}$, enquanto Montoya \& Chaves (1974) citam, sob temperatura de $24^{\circ} \mathrm{C}$, a máxima porcentagem de germinação, ou seja, 23,66\%. As diferenças encontradas podem ser em

\footnotetext{
1'Doutor em Fitopatologia - Departamento de Fitopatologia/DFP - Universidade Federal de Lavras/UFLA - Cx. P. 3037 - $37200-000$ - Lavras, MG msalustiano@yahoo.com.br - Bolsista RD do CNPq

${ }^{2}$ Doutores em Fitopatologia, Professores - Departamento de Fitopatologia/DFP - Universidade Federal de Lavras/UFLA - Cx. P. 3037 - $37200-000$ Lavras, MG - eapozza@ufla.br; ealves@ufla.br

${ }^{3}$ Mestrando em Engenharia Florestal - Departamento de Ciências Florestais/DCF - Universidade Federal de Lavras/UFLA - Cx. P. 3037 - $37200-000$ Lavras, MG - acferrazfilho@gmail.com - Bolsista de Iniciação Científica do CNPq

${ }^{4}$ Doutorando em Fitopatologia - Departamento de Fitopatologia/DFP - Universidade Federal de Lavras/UFLA - Cx. P. 3037 - $37200-000$ - Lavras, MG aobotelho@yahoo.com.br
} 
conseqüência da metodologia empregada ou à variabilidade do patógeno. Em relação ao comprimento do tubo germinativo, Saccas \& Charpentier (1971) encontraram o maior comprimento a $24^{\circ} \mathrm{C}$, na presença de um filme de água, enquanto Montoya \& Chaves (1974) afirmaram ser o comprimento do tubo germinativo sempre crescente (169 a $582 \mathrm{~mm}$ ), com o aumento da temperatura nos intervalos de $18^{\circ} \mathrm{C}, 20^{\circ} \mathrm{C}, 22^{\circ} \mathrm{C}, 24^{\circ} \mathrm{C}$ e $26^{\circ} \mathrm{C}$. Ou seja, após iniciado o processo germinativo, mesmo em condições de temperaturas adversas, ocorreu crescimento do tubo germinativo.

Também para outras ferrugens foram realizados estudos sobre as influências da temperatura na germinação e no crescimento do tubo germinativo, como a ferrugem da lentilha (Uromyces viciae-fabae (Pers.)) (ELLISON et al., 1990, 1992; NEGUSSIE et al., 2005). Segundo Negussie et al. (2005), os urediniósporos da ferrugem da lentilha germinaram em mais de $80 \%$ a $10^{\circ} \mathrm{C}, 15^{\circ} \mathrm{C}, 20^{\circ} \mathrm{C}$ e $25^{\circ} \mathrm{C}$ e o comprimento do tubo germinativo foi de $66 \mathrm{~mm}$ e $196 \mathrm{~mm}$, a $10^{\circ} \mathrm{C}$ e $20^{\circ} \mathrm{C}$, respectivamente.

Portanto, o microclima específico de cada região brasileira pode influenciar as diversas fases da relação patógeno-hospedeiro, desde a germinação até a colonização (AKUTSU, 1981). Diante disso, neste trabalho, objetivou-se verificar o efeito da temperatura na germinação e no comprimento do tubo germinativo em diferentes populações de urediniósporos de $H$. vastatrix sob condições controladas.

O experimento foi realizado no Laboratório de Epidemiologia do Departamento de Fitopatologia da Universidade Federal de Lavras. Utilizaram-se dez populações de $H$. vastatrix (PHV) coletadas em plantas de café da cultivar Catuaí localizadas em seis municípios de Minas Gerais: Cajuri (CAJ2 e CAJ3, Coromandel (CO2), Ijaci (IIJ1), Lavras (LA1, LA2 e UFLA), São Miguel do Anta (SMA e SMA3) e Viçosa (VIC). As PHVs foram coletadas em folhas de cafeeiro com pústulas uniformes e livres de contaminação por hiperparasitas e ácaros. Os urediniósporos coletados foram peneirados a 100 mesh para homogeneização e eliminação das impurezas. A viabilidade dos urediniósporos foi preservada acondicionando-os em microtubos, colocados em dessecador contendo solução de ácido sulfúrico a 32,6\%, para manter a umidade relativa do ar em $50 \%$ (ZAMBOLIM, 1973).

As PHVs foram multiplicadas em mudas da cultivar Catuaí, com três meses de idade. Para cada PHV, inocularamse três mudas de cafeeiro com suspensão de $0,5 \mathrm{mg} / \mathrm{mL}$ de urediniósporos de $H$. vastatrix, em solução aquosa $(0,05 \%)$ de tween 80. Após a inoculação, as plantas foram mantidas em câmara úmida, utilizando-se sacos plásticos escuros, durante 72 horas, sob temperatura de $23^{\circ} \mathrm{C}$. Após esse período, os sacos plásticos foram retirados e as plantas mantidas nas mesmas condições ambientais para a produção de novos urediniósporos.

Com a produção de novas pústulas em todas as PHVs, um bioensaio foi conduzido em lâminas de microscópio recobertas com camada de poliestireno (LEITE \& NICHOLSON, 1992) e acondicionadas em gerboxes contendo papel de filtro umedecido para preservar a umidade. Para cada PHV, preparou-se suspensão de urediniósporos como citado anteriormente. Duas gotas da suspensão foram colocadas eqüidistantes sobre a lâmina contida em cada gerbox, os quais foram mantidos fechados no escuro, a $15^{\circ} \mathrm{C}, 20^{\circ} \mathrm{C}, 25^{\circ} \mathrm{C}$ e $30^{\circ} \mathrm{C}$. O ensaio foi conduzido em fatorial $10 \mathrm{x} 4$, sendo dez isolados, quatro temperaturas e duas repetições (duas gotas de $50 \mathrm{~mL}$ da suspensão por repetição) As avaliações da germinação e do crescimento do tubo germinativo foram realizadas 24 horas após a deposição dos urediniósporos, contando-se ao microscópio 200 esporos e medindo-se o comprimento do tubo germinativo de 30 urediniósporos/repetição.

As análises estatísticas foram realizadas utilizandose o PROC GLM do programa SAS. Os valores de porcentagem de germinação e comprimento do tubo germinativo, após serem transformados em $\operatorname{arcsen} \sqrt{\frac{x}{100}} \mathrm{e}$ $\sqrt{x+0,5}$, respectivamente, foram submetidos aos testes de Shapiro-Wilk e de Hartley para os quais apresentaram normalidade e homogeneidade de variância. As variáveis significativas no teste $\mathrm{F}$, da análise de variância, foram comparadas pelo teste Tukey a $5 \%$.

Houve interação significativa para a germinação entre as PHVs com as temperaturas. Todas as PHVs (IIJI, ILA1, SMA, ILA2, UFLA, CAJ3, CAJ2, SMA3, VIC, CO2) provenientes de seis municípios produtores de café do estado de Minas Gerais germinaram a $15^{\circ} \mathrm{C}, 2^{\circ} \mathrm{C}, 25^{\circ} \mathrm{C}$ e $30^{\circ} \mathrm{C}$ (Figuras 1 e 2 ).

Em todas as temperaturas, as diferenças de porcentagem de germinação entre os isolados estiveram entre 4,5 e $53 \%$. A máxima porcentagem de germinação foi de $53 \%$ para $\mathrm{CO} 2$ a $20^{\circ} \mathrm{C}$ e a mínima de $4,5 \%$ para VIC a $15^{\circ} \mathrm{C}$. Ao considerarem-se as diferentes PHVs, nota-se que valores superiores a $40 \%$, de germinação foram encontrados a $20^{\circ} \mathrm{C}\left(\mathrm{CO} 2\right.$, IIJI, ILA1), a $25^{\circ} \mathrm{C}$ (IIJI, ILA1) e a $30^{\circ} \mathrm{C}$ (IIJI). Evidencia-se, portanto, a ocorrência de maiores valores de germinação, inclusive a $30^{\circ} \mathrm{C}$, considerado limitante por Nutman \& Roberts (1963) e Saccas \& Chapentier (1971). A $15^{\circ} \mathrm{C}$, os valores de germinação superiores a $20 \%$ foram encontrados em CO2 (39,6\%), ILA1 (37\%), CAJ2 (31,5\%), IIJI (26\%) e CAJ3 (20,6\%). 

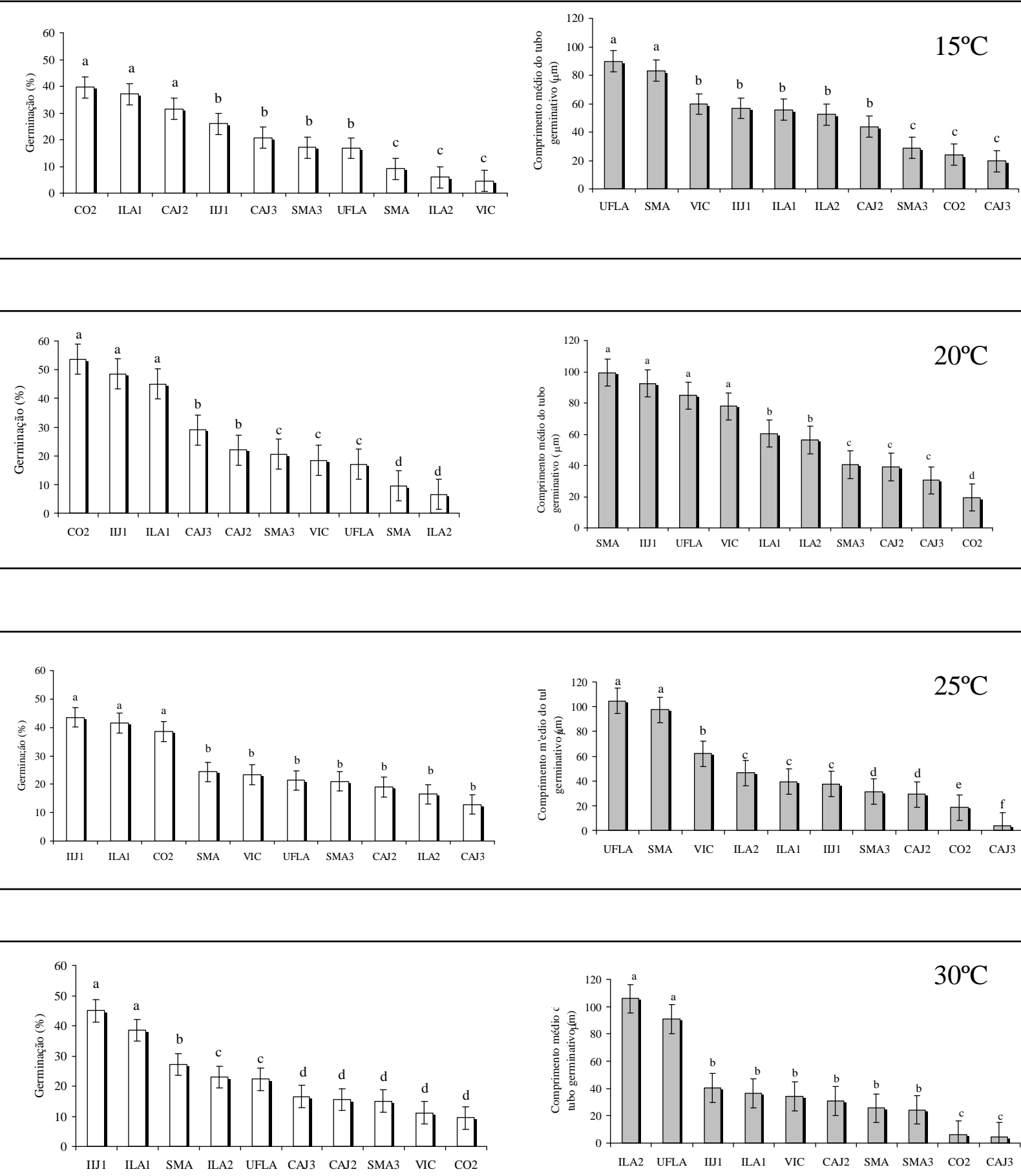

Figura 1 - Efeito das temperaturas de A) $15^{\circ} \mathrm{C}$, B) $20^{\circ} \mathrm{C}$, C) $25^{\circ} \mathrm{C}$ e D) $30^{\circ} \mathrm{C}$ na germinação e no comprimento do tubo germinativo de dez populações de Hemileia astatrix. As barras indicam o erro padrão da média. 

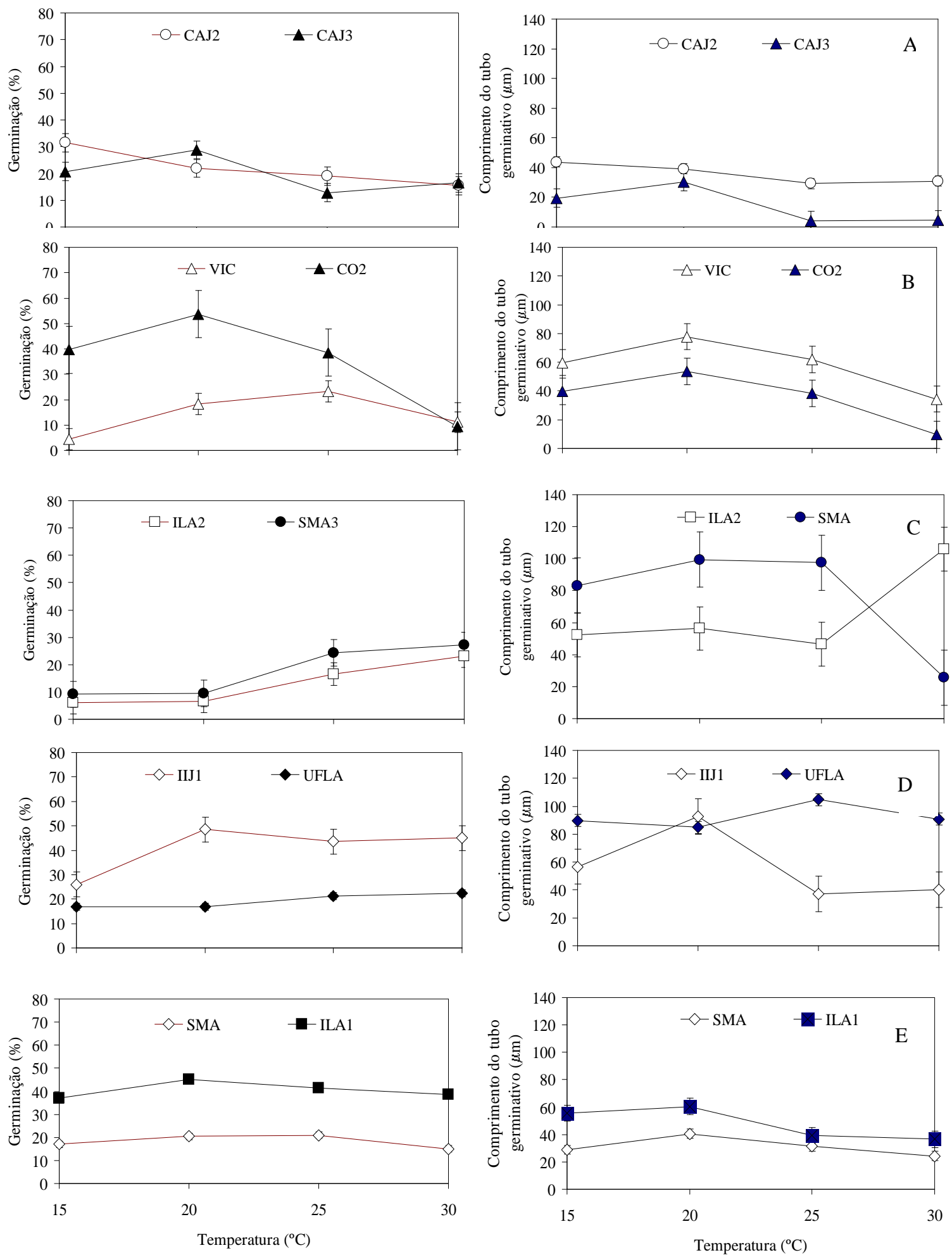

Figura 2 - Germinação e comprimento do tubo germinativo das PHVs- A) CAJ2 e CAJ3, B) CO2 e VIC, C) SMA e ILA2, D) IFLA e IIJ1, E) SMA e ILA1 em quatro temperaturas. As barras indicam o erro padrão da média. 
Também houve pequena variação em algumas PHVs quando comparadas entre as temperaturas (Figura 2). Por exemplo, $\mathrm{CO} 2$ apresentou maiores valores de germinação a $15^{\circ} \mathrm{C}, 20^{\circ} \mathrm{C}$ e $25^{\circ} \mathrm{C}$, IIJI a $20^{\circ} \mathrm{C}, 25^{\circ} \mathrm{C}$ e $30^{\circ} \mathrm{C}$, ILA 1 a $15^{\circ} \mathrm{C}$, $20^{\circ} \mathrm{C}, 25^{\circ} \mathrm{C}$ e $30^{\circ} \mathrm{C}$. Algumas PHVs apresentaram o ótimo de germinação entre $25^{\circ} \mathrm{C}$ e $30^{\circ} \mathrm{C}$, valores antes considerados limitantes para a germinação de $H$. vastatrix por alguns autores (NUTMAN \& ROBERTS, 1963; SACCAS \& CHAPENTIER, 1971). Há predominância de climas diferentes nas diversas regiões e podem existir PHVs adaptadas a estes climas e até mesmo ao aumento na temperatura média ocorrido nos últimos anos.

De acordo com Chalfoun et al. (2001), a ocorrência de temperaturas mais elevadas e chuvas ocasionais no período de outono-inverno entre 1991 a 1995 mantiveram elevados índices de ferrugem do cafeeiro, prolongando o ciclo até agosto. Além disso, também existem diferenças de clima entre as regiões onde o cafeeiro é cultivado. As temperaturas mínimas médias noturnas estiveram, em média, a $18^{\circ} \mathrm{C}$ em Coromandel e Viçosa, a $16^{\circ} \mathrm{C}$ em Lavras, Cajuri e São Miguel do Anta e a $14^{\circ} \mathrm{C}$ em Ijaci (BRASIL, 2005; OLIVEIRA, 2005). Portanto, a diferença entre as temperaturas ótimas para germinação encontrada por Akutsu (1981), Dejong et al. (1987), Montoya \& Chaves (1974), Nutman \& Roberts (1963), Rayner (1972) e Saccas \& Charpentier (1971), pode ser devido à variabilidade entre populações, as quais foram selecionadas de acordo com o microclima de cada região.

Quanto ao comprimento do tubo germinativo, também houve interação entre as temperaturas e as PHVs. Em cada temperatura ocorreram diferenças significativas entre as populações, podendo variar de 4,0 a $105 \mathrm{~mm}$, como na temperatura de $25^{\circ} \mathrm{C}$. Os valores máximo $(105 \mathrm{~mm}) \mathrm{e}$ mínimo (4mm) do comprimento do tubo germinativo foram encontrados em ILA2 a $30^{\circ} \mathrm{C}$ e $\mathrm{CAJ} 3$ a $25^{\circ} \mathrm{C}$, respectivamente (Figura 1). Geralmente, as populações com menor germinação apresentaram os maiores comprimentos do tubo germinativo. Segundo Montoya \& Chaves (1974), o crescimento do tubo germinativo no intervalo de $18^{\circ} \mathrm{C}$ a $26^{\circ} \mathrm{C}$, sempre foi crescente, variando de $169,03 \mathrm{~mm}$ a $582,9 \mathrm{~mm}$, mesmo com a redução na germinação a partir de $22^{\circ} \mathrm{C}$, embora algumas PHVs, tenham apresentado menor comprimento do tubo germinativo nas temperaturas de $25^{\circ} \mathrm{C}$ e $30^{\circ} \mathrm{C}\left(\mathrm{CAJ} 3\right.$, ILA1, IIJI) e a $30^{\circ} \mathrm{C}(\mathrm{CO} 2$, VIC, SMA). Para determinadas $\mathrm{PHVs}$, a temperatura acima de $20^{\circ} \mathrm{C}$ pode comprometer ou desacelerar o processo germinativo. As condições favoráveis à germinação nem sempre são favoráveis ao crescimento do tubo germinativo que, de acordo com Coutinho et al. (1993) e Dejong et al. (1987), deve ser, no mínimo, de 100mm para alcançar os estômatos, eqüidistantes $70 \mathrm{~mm}$ no café arábica. $\mathrm{O}$ comprimento máximo do tubo de $\mathrm{CO} 2$ chegou a $24 \mathrm{~mm}$, valor considerado baixo, no entanto, apresentou altos valores de germinação.Há, portanto, necessidade de seleção criteriosa das zonas geográficas cafeicultoras, a fim de caracterizar a variabilidade das populações de $H$. vastatrix, para melhor compreensão da dinâmica de suas populações, bem como, da sua evolução.

\section{REFERÊNCIAS BIBLIOGRÁFICAS}

AKUTSU, M. Relações de funções climáticas e bióticas com a taxa de infecção da ferrugem do cafeeiro (Hemileia vastatrix Berk et Br.). 1981. 67 f. Dissertação (Mestrado em Fitopatologia) - Universidade Federal de Viçosa, Viçosa, 1981.

BRASIL. Ministério da Agricultura Pecuária e Abastecimento. Agritempo: sistema de monitoramento agrometeorologico. Disponível em: <http:// WWw.agritempo.gov.bri>. Acesso em: 12 dez. 2005.

CHALFOUN, S. M.; CARVALHO, V. L.; PEREIRA, M. C. Efeito de alterações climáticas sobre o progresso da ferrugem (Hemileia vastatrix Berk. \& Br.) do cafeeiro. Ciência e Agrotecnologia, Lavras, v. 25, n. 5, p. 1248-1252, set./out. 2001.

COUTINHO, T. A.; FIJKENBERG, F. H. J.; VANASCH, M. A. J. Apressorium formation by Hemileia vastatrix. Mycological Research, New York, v. 97, n. 8, p. 951-956, Aug. 1993.

DEJONG, E. J.; ESKES, A. B.; HOOGSTRATEN, I. G. J.; ZADOKS, J. C. Temperature requirements for germination, germ tube growth and appressorium formation of urediniospores of Hemileia vastatrix. Netherlands Journal of Plant Pathology, Wageningen, v. 93, n. 2, p. 61-71, Feb. 1987.

ELLISON, P. J.; CULLIS, B. R.; BAMBACH, R. W.; KABLE, P. F. The effect of temperature on in vitro germination and germ tube growth of Tranzschelila discolor. Australian Journal of Agricultural Research, Collingwood Victoria, v. 41, n. 3, p. 479-488, Mar. 1990.

ELLISON, P. J.; CULLIS, B. R.; BAMBACH, R. W.; KABLE, P. F. The effect of light and temperature on in vitro germination and germ tube growth of Tranzschelila discolor. Australian Journal of Agricultural Research, Victoria, v. 43, n. 1, p. 451-454, Jan. 1992. 
LEITE, B.; NICHOLSON, R. Micosporine-Alanine: a selfinhibitor of germination from the conidial mucilage of Colletotrichum graminicola. Experimental Mycology, Piracicaba, v. 16, n. 1, p. 76-86, 1992.

MONTOYA, R. H.; CHAVES, G. M. Influência da temperatura e da luz na germinação, infectividade e período de geração de Hemileia vastatrix Berk. \& Br. Experientiae. Ceres, Viçosa, v. 18, n. 11, p. 239-266, dez. 1974.

NEGUSSIE, T.; PRETORIUS, Z. A.; BENDER, C. M. Effect of some environmental factors on in vitro germination of urediniospores and infection of lentils by rust. Journal of Phytopathology, Berlin, v. 153, n. 1, p. 43-47, Jan. 2005.

NUTMAN, E. J.; ROBERTS, F. M. Studies on the biology of Hemileia vastatrix Berk. et Br. Transactions of Britisth Mycological Society, Cambridge, v. 46, n. 1, p. 27-48, Jan. 1963.

OLIVEIRA, F. A. Validação de modelos de previsão da ferrugem do cafeeiro e monitoramento de esporos de
Hemileia vastatrix e Cercospora coffeicola em Lavras, MG. 2005. 98 f. Tese (Doutorado em Fitopatologia) Universidade Federal de Lavras, Lavras, 2005.

RAYNER, R. W. Micologia y biologia de la roya del cafeto. Turrialba: Instituto Interamericano de Ciências Agrícolas de la O E A, 1972. 175 p.

SACCAS, A. M.; CHARPENTIER, J. La rouille des caféiers due a Hemileia vastatrix Berk. \& Br. Paris: Institur Français du Café, du Cacau et otres Plantes Stimulantes, 1971. 123 p. (Bulletin, 10).

ZADOKS, J. C.; SCHEIN, R. D. Epidemiology and plant disease management. Oxford: University of Oxford, 1979. $427 \mathrm{p}$.

ZAMBOLIM, L. Efeito de baixas temperaturas e do binômio temperatura-umidade relativa sobre a viabilidade dos uredósporos de Hemileia vastatrix Berk. et Br. e Uromyces phaseoli typica Arth. 1973. 52 f. Dissertação (Mestrado) - Universidade Federal de Viçosa, Viçosa, 1973. 